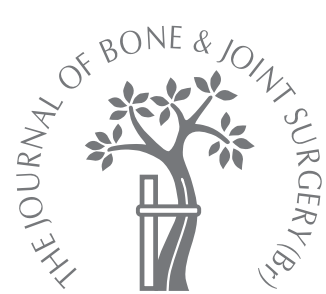

T. Boyer,

H. Dorfmann

From I. A. L Nollet, Paris, France

\title{
Arthroscopy in primary synovial chondromatosis of the hip
}

\author{
DESCRIPTION AND OUTCOME OF TREATMENT
}

In T. Boyer, MD,

Rheumatologist, Past President of the French Arthroscopy Association

H. Dorfmann, MD

Rheumatologist,

IAL Nollet, 23 rue Brochant,

75017 Paris, France.

Correspondence should be sent to Dr T. Boyer; e-mail: thierry.boyer13@wanadoo.fr

(C)2008 British Editorial Society of Bone and Joint Surgery doi:10.1302/0301-620X.90B3 $19664 \$ 2.00$

$J$ Bone Joint Surg $[\mathrm{Br}]$ 2008:90-B:314-18

Received 9 May 2007; Accepted after revision 14 November

2007

\begin{abstract}
Between 1985 and 2000, 120 patients underwent arthroscopic management for primary synovial chondromatosis of the hip. We report the outcome of 111 patients with a mean follow-up of 78.6 months (12 to 196). More than one arthroscopy was required in 23 patients $(20.7 \%)$, and 42 patients $(37.8 \%)$ went on to require open surgery. Outcomes were evaluated in greater detail in 69 patients $(62.2 \%)$ treated with arthroscopy alone, of whom $51(45.9 \%)$ required no further treatment and $18(16.2 \%)$ required further arthroscopies. Of the 111 patients, $63(56.7 \%)$ had excellent or good outcomes. At the most recent follow-up, 22 patients $(19.8 \%)$ had undergone total hip replacement.

Hip arthroscopy proved beneficial for patients diagnosed with primary synovial chondromatosis of the hip, providing good or excellent outcomes in more than half the cases.
\end{abstract}

Primary synovial chondromatosis of the hip is a rare condition of unknown aetiology. ${ }^{1,2}$ Synovial membrane metaplasia is the primary abnormality in this condition, whereas loose body formation in secondary osteochondromatosis is a consequence of the development of osteoarthritis (OA). Very little epidemiological data on primary synovial chondromatosis of the hip has been published and there are no case series reporting the value of arthroscopyassisted treatment.

\section{Patients and Methods}

We retrospectively evaluated 111 consecutive patients from a series of 120 who underwent arthroscopic treatment for primary synovial chondromatosis of the hip between 1985 and 2000, by two surgeons (TB, HD). Nine patients had been lost to follow-up.

There were 57 women and 54 men, with a mean age of 43.3 years (13 to 81 ). The right hip was involved in 63 patients and the left hip in 48 . The mean duration of symptoms at the time of arthroscopy, which was known for 75 patients, was 31 months (6 to 60). Of 30 patients for whom the mode of onset was recorded, $21(70 \%)$ had a gradual onset and 7 $(23.3 \%)$ an acute onset. Radiographs taken for an unconnected reason provided the diagnosis in two patients $(6.7 \%)$.

Mechanical pain was reported by $93 \%$ (66 of 71) of patients. Intermittent pain was experienced by $84 \%$ (74 of 88 ), with the remainder $(16 \%)$ reporting continuous pain. In 35 patients $(31.5 \%)$, walking or engaging in sports or other physical activities worsened the pain. On examination, there was a limited range of movement in 57 patients $(51.4 \%)$ and a limp in $11(9.9 \%)$.

A questionnaire was sent to all patients and those who did not respond were contacted by telephone or given an appointment. The questionnaire included a 100-point overall satisfaction scale, a 10-point visual analogue scale (VAS) for pain, and a three-level mobility scale (normal, somewhat restricted, and markedly restricted). In addition, information was collected on any medical and surgical treatments that may have been undertaken subsequent to the arthroscopy of the hip. We defined an excellent outcome as one with $>75 \%$ subjective improvement with no pain or limitation of movement, and a good outcome as one with $>50 \%$ subjective improvement with minimal pain and no limitation of movement. Any other outcome was considered a failure.

Over the 15-year period covered by this study, the nature of the radiological assessment changed. Routine radiographs were obtained in all patients. In addition, 29 patients $(26.1 \%)$ underwent arthrography, 44 (39.6\%) CT arthrography, 15 (13.5\%) MR scanning, and $\operatorname{six}(5.4 \%)$ radionuclide bone scanning. Preoperative imaging studies established the diagnosis in 71 patients $(63.9 \%)$, including 55 $(49.5 \%)$ with osteochondromas visible on rou- 


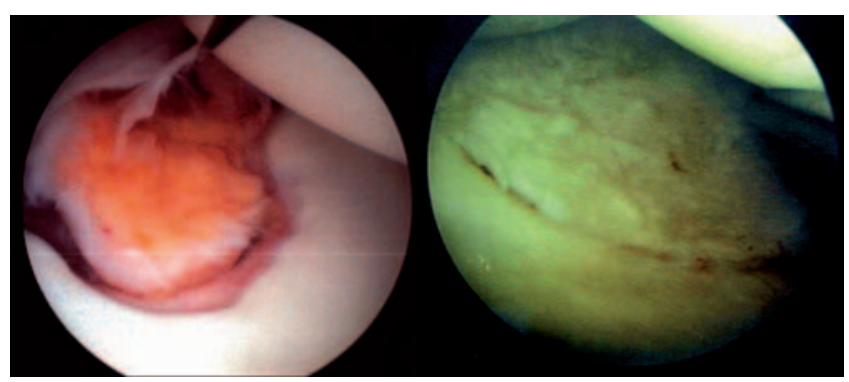

Fig. 1a

Fig. 1b

a) The normal arthroscopic appearance and b) the pancake-like clump of chondromatosis.

tine radiographs, and suggested the diagnosis in $31(28 \%)$. In eight patients $(7.2 \%)$, no diagnosis had been established pre-operatively, and in one $(0.9 \%)$ a mistaken diagnosis of synovitis was corrected by the arthroscopy findings.

Arthroscopy technique. Under general anaesthesia, the patient was placed in the supine position. Two techniques were used, one for each of the two compartments of the joint. The peripheral compartment was visualised without traction via an anterolateral portal ${ }^{3,4}$ with the instruments introduced through a distal anterolateral portal. For the central compartment traction was applied, with countertraction applied by the central post. For this compartment the lateral, anterolateral and, if needed, posterolateral portals, as described by Glick et al, ${ }^{5}$ were used. Where the loose bodies had been located previously by CT and arthrography, ${ }^{6}$ only the required compartment was entered to avoid unnecessary exposure to potential adverse events related to the counterpost. ${ }^{7}$

Any loose bodies were removed using probes and/or graspers, according to their type and size (Fig. 1). In addition, some were crushed in situ and removed by lavage. The disease was staged according to the Milgram method, ${ }^{8}$ in which stage I comprises chondroma formation in the synovium without loose bodies, stage II is chondroma formation in the synovium with loose bodies and stage III is loose bodies without ongoing chondroma formation in the synovium.

\section{Results}

The mean follow-up since arthroscopy for the 111 patients was 78.6 months (12 to 196). The lesions were confined to the peripheral compartment in 76 patients $(68.5 \%)$ and in the remaining $35(31.5 \%)$ traction was used alone or combined with the peripheral technique. A total of 23 patients had more than one arthroscopy so that 148 arthroscopies were performed; 88 had one, 20 had two, two had three, and one had five. The nine patients lost to follow-up all had one. By 2002, 42 patients $(37.8 \%$ ) had required open surgery, including total hip replacement (THR) in 19 (17.1\%), synovectomy in $12(10.8 \%)$ and open removal of loose bodies in 11 (9.9\%). Their outcome is not reported further. A total of 69 patients $(62.2 \%)$ had undergone arthroscopic treatment only, with further arthroscopy being required in $18(16.2 \%)$.

Arthroscopy. In 53 patients $(47.7 \%)$ arthroscopy showed active chondromatosis with ongoing chondroma formation in the synovial membrane. Among them, six patients $(5.4 \%)$ had Milgram stage I and $47(42.3 \%)$ Milgram stage II disease. Pedunculated lesions were found in 34 patients, sessile lesions in 11, and both in eight. Of the 47 patients with stage II disease, 25 had chondromas, 12 had osteochondromas and 10 had both. The remaining 58 patients $(52.3 \%)$ had Milgram stage III disease, of whom 25 had chondromas, 14 had osteochondromas, and 19 had both.

Loose chondromas (composed only of cartilage) were seen as separate rice bodies in 46 patients $(41.4 \%)$ and as clumps of rice bodies of variable size and shape in 25 $(22.5 \%)$. In addition, six patients each had a solitary pancake-like clump of coalesced loose bodies. Bead-like chondromas were found in eight patients and empty cartilaginous sacs in three. Several patients had more than one type of chondroma.

Chondromas were peripheral in 52 patients, central in five, and both in 22. Osteochondromas (cartilage and bone) were peripheral in 34 patients, central in six, and both in 14. Osteochondromas confined to the iliopsoas bursa were found in one patient. Finally, five patients had multiple osteochondromas embedded in the synovium, which had become hardened and inflexible.

The appearance of the articular cartilage of the hip joint was not recorded in 17 patients $(15.3 \%)$. In 61 patients $(54.9 \%)$ the cartilage was considered normal, in 21 $(18.9 \%)$ some damage was noted on articular surfaces, and osteophytosis was found in $12(10.9 \%)$.

Complications. No cases of infection, thromboembolism or other major complications ${ }^{9}$ were recorded. Chondrosarcoma, which is an exceedingly rare complication of hip chondromatosis, ${ }^{10-12}$ did not occur in any of the patients. Reflex sympathetic dystrophy developed in two patients. Arthroscopy outcome. The outcome was evaluated of the 69 patients $(62.2 \%)$ who by 2002 had not required any treatment in addition to arthroscopy. The mean age at arthroscopy in this group was 37.5 years (16 to 81 ), compared with 44.7 years (18 to 77 ) in the group of 42 patients $(37.8 \%)$ who had already required open surgery (Table I). A total of 51 patients $(45.9 \%)$ had required no further arthroscopic treatment; their mean age was 39.4 years $(20$ to 63$)$. The remaining 18 patients $(16.2 \%)$ had required repeated arthroscopic procedures; their mean age at the first arthroscopy was 32.3 years (13 to 58 ). The mean time between the first and second arthroscopies was three years (1 to 14 ) (Table II). Of these 18 patients, eight had an excellent outcome, nine had a good outcome, and the treatment failed in one.

Failures of arthroscopic treatment. Among the 42 patients in whom arthroscopic treatment had failed and who had 
Table I. Outcomes in the 69 patients treated with arthroscopy alone

\begin{tabular}{llll}
\hline & Number of patients & $\begin{array}{l}\text { Percentage of subgroup } \\
(\mathbf{n}=\mathbf{6 9})\end{array}$ & $\begin{array}{l}\text { Percentage of whole } \\
\text { series }(\mathbf{n}=\mathbf{1 1 1})\end{array}$ \\
\hline Excellent & 40 & 58 & 36 \\
Good & 23 & 33 & 20 \\
Failure & 6 & 9 & 5 \\
\hline
\end{tabular}

Table II. Time between the first and second arthroscopy in the 18 patients who had more than one arthroscopy but no open surgery

\begin{tabular}{lllllll}
\hline & \multicolumn{2}{l}{ Year } & & & & \\
\cline { 2 - 7 } & $<\mathbf{1}$ & $\mathbf{3}$ & $\mathbf{4}$ & $\mathbf{5}$ & $\mathbf{6}$ & $\mathbf{1 4}$ \\
\hline Number of patients & 10 & 3 & 1 & 1 & 2 & 1 \\
\hline
\end{tabular}

required open surgery, five had received more than one arthroscopy. A total of $19(17.1 \%)$ had required THR although in three this seemed unrelated. One patient had avascular necrosis 12 years after a good outcome from arthroscopy, one had ankylosing spondylitis, and one had multiple epiphyseal dysplasia. Nevertheless, we counted these three patients among the failures of arthroscopic treatment.

In addition, six patients were classified as failure because they had a poor outcome after one or more arthroscopic procedures, although they had not required open surgery. Three of these patients were receiving medical treatment for established OA of the hip.

Outcomes according to disease activity. Of the 69 patients treated with arthroscopy only, 31 (45\%) had active disease at the time of the procedure (Milgram stage I or II) and 38 (55\%) had quiescent disease (Milgram stage III). Of the 42 patients who required open surgery, 21 (50\%) had active disease and $21(50 \%)$ quiescent disease at the time of the arthroscopy. The combined influence of disease activity and loose body type in the 69 patients treated with arthroscopy only is reported in Table III. The age distribution by type of chondromatosis for the whole series is shown in Table IV.

\section{Discussion}

Our overall findings are consistent with those of earlier reports. ${ }^{1,2,13,14}$ Our patients were somewhat older than expected for a disease that predominates in the 20- to 40year age group. The symptoms, course and findings from investigations were typical. In contrast to earlier series more than half of the patients were women.

Primary synovial chondromatosis of the hip is a disease of unknown cause that is challenging to manage. ${ }^{15-17}$ The lesions usually remain confined to a single hip, with ensuing damage to the articular cartilage leading to OA. Few series or case reports on the arthroscopic or open surgical management of primary synovial chon- dromatosis of the hip are available. ${ }^{13,18-21}$ Several publications mention that arthroscopy is useful, ${ }^{22}$ and report a limited number of cases. ${ }^{18,20}$ In a series of 30 hip arthroscopies, two patients had primary synovial chondromatosis of the hip. ${ }^{23}$ Schoeniger et $\mathrm{al}^{24}$ reported on the treatment of eight patients by open synovectomy with hip distraction. Follow-up was at least four years in all patients, with a mean follow-up of 6.5 years during which time no recurrences were found, but subsequently THR had been performed in two patients. Lim et $\mathrm{al}^{25}$ achieved favourable outcomes with open surgery in 21 patients with a mean follow-up of 4.4 years.

Previously we reported that simple removal of loose bodies was beneficial in patients with chondromatosis involving the knee. $^{26}$ We have found that arthroscopic treatment is beneficial in primary synovial chondromatosis of the hip. Even with the most conservative estimate, counting as failures the 42 patients $(37.8 \%)$ who required open surgery and the six $(5.4 \%)$ with failed arthroscopic treatment but no open surgery at the time of the study, 63 patients $(56.7 \%)$ were satisfied with the arthroscopic procedure. Of the 69 patients who underwent arthroscopic treatment alone, $40(58 \%)$ had an excellent outcome. Overall, arthroscopic treatment was beneficial in more than half the patients and produced an excellent outcome in more than one-third.

We tried to identify factors that determined the outcome. Disease activity as assessed by Milgram ${ }^{8}$ stage at arthroscopy did not appear to influence the need for open surgery later on (Table V). Nevertheless, in the group of patients treated with arthroscopy only, an excellent outcome was achieved in 26 of 38 patients $(68 \%)$ with quiescent disease, compared with only 14 of 31 patients $(45 \%)$ with active disease (Table III). Similarly, the disease was active in nine of the 18 patients who had more than one arthroscopic procedure but no open surgery, compared with four of five patients who had open surgery after repeat arthroscopy. The time between the first and second arthroscopic procedures appeared to have no impact on the outcome. Excellent outcomes were achieved at all time intervals, including the patient with a 14-year interval. We were unable to determine whether the status of the cartilage affected the failure rate, but many of the earlier patients did not undergo visualisation of the central compartment, which may have resulted in underestimation of the damage to the articular cartilage. Finally, older age at the time of arthroscopy seemed to be associated with a worst 
Table III. Combined influence of disease activity and loose body type on outcome in the 69 patients treated with arthroscopy alone. Values are numbers of patients

\begin{tabular}{|c|c|c|c|c|c|c|}
\hline \multirow[b]{2}{*}{ Outcomes } & \multicolumn{3}{|c|}{ Quiescent disease } & \multicolumn{3}{|c|}{ Active disease } \\
\hline & Excellent & Good & Failure & Excellent & Good & Failure \\
\hline Chondromas only & 9 & 7 & 0 & 5 & 4 & 0 \\
\hline Osteochondromas only & 6 & 2 & 0 & 4 & 1 & 3 \\
\hline Chondromas + osteochondromas & 11 & 3 & 0 & 5 & 5 & 2 \\
\hline Milgram stage I & & & & 0 & 1 & 1 \\
\hline Total & 26 & 12 & 0 & 14 & 11 & 6 \\
\hline
\end{tabular}

Table IV. Age distribution by disease activity and loose body type among the 111 patients

\begin{tabular}{|c|c|c|c|c|c|c|}
\hline \multirow[b]{2}{*}{ Type of loose body } & \multicolumn{2}{|l|}{ Quiescent } & \multicolumn{2}{|l|}{ Active } & \multicolumn{2}{|l|}{ Overall } \\
\hline & $\begin{array}{l}\text { Number of } \\
\text { patients }\end{array}$ & $\begin{array}{l}\text { Mean age } \\
\text { (yrs) }\end{array}$ & $\begin{array}{l}\text { Number of } \\
\text { patients }\end{array}$ & $\begin{array}{l}\text { Mean age } \\
\text { (yrs) }\end{array}$ & $\begin{array}{l}\text { Number of } \\
\text { patients }\end{array}$ & $\begin{array}{l}\text { Mean age } \\
\text { (yrs) }\end{array}$ \\
\hline Chondromas only & 25 & 40.1 (23 to 62 ) & 25 & 41.2 (13 to 63$)$ & 50 & 40.6 \\
\hline Osteochondromas only & 14 & 38.7 (23 to 58 ) & 12 & 41.8 (22 to 72$)$ & 26 & 40.1 \\
\hline Chondromas + osteochondromas & 19 & $34.3(18$ to 81$)$ & 10 & 32.5 (21 to 42$)$ & 29 & 33.7 \\
\hline No loose bodies & & & 6 & 50.1 (30 to 61$)$ & & \\
\hline Overall & 58 & $37.7(18$ to 81$)$ & 53 & 41.4 (13 to 72$)$ & & \\
\hline
\end{tabular}

Table V. Type of treatment by disease activity in the 111 patients who underwent arthroscopic treatment for primary synovial chondromatosis of the hip

\begin{tabular}{llll}
\hline & Quiescent & Active & Total \\
\hline Arthroscopy & 38 & 31 & 69 \\
Arthroscopy + open surgery & 21 & 21 & 42 \\
\hline
\end{tabular}

outcome. The mean age was 44.7 years in the 42 patients who underwent open surgery and 37.5 years in the 69 patients treated with arthroscopy only. It is unlikely that this apparent difference can be ascribed to later treatment, as the mean time from the onset of symptoms to the first arthroscopic procedure was similar in the two groups (33.5 months in the open-surgery group and 29.2 months in the arthroscopy-only group). Similarly, the mean time since the first arthroscopic procedure was 70.7 months in the opensurgery group and 83.3 months in the arthroscopy-only group.

Primary synovial chondromatosis of the hip is a rare condition with an unknown aetiology. The natural history is unpredictable and the treatment challenging. Although our study is limited by its retrospective design, the large number of patients and the long mean followup of 78.6 months provide credibility. Hip arthroscopy can be beneficial for patients with this condition and it provided a good or excellent outcome in more than half the patients in our series.

No benefits in any form have been received or will be received from a commercial party related directly or indirectly to the subject of this article.

\section{References}

1. Lequesne $\mathbf{M}$, Mathieu $\mathbf{P}$, Winkler $\mathbf{P}$. La chondromatose synoviale de la hanche. Rev Rhum 1999;66(Suppl):41-7.

2. Murphy FP, Dahlin DC, Sullivan CR. Articular synovial chondromatosis. J Bone Joint Surg [Am] 1962;44-A:77-86.

3. Dienst M, Gödde S, Seil R, Hammer D, Kohn D. Hip arthroscopy without traction: in vivo anatomy of the peripheral hip joint cavity. Arthroscopy 2001;17:924-31.

4. Dorfmann H, Boyer Th, Henry P, De Bie B. A simple approach to hip arthroscopy. Arthroscopy 1988;4:141-2 (abstract).

5. Glick JM, Sampson TG, Gordon RB, Behr JT, Schmidt E. Hip arthroscopy by the lateral approach. Arthroscopy 1987;3:4-12.

6. Cotten A, Demondion X, Boutry N, Chastanet P, Delfaut E. Imaging of synovial lesions, neoplastic or non-neoplastic. J Radiol 2000;81(3 suppl):390-1 (in French).

7. Locker B, Beguin J. L'arthroscopie de hanche. J Med Lyon 1984;1394:25-6.

8. Milgram JW. Synovial osteochondromatosis: a histopathological study of thirty cases. J Bone Joint Surg [Am] 1977;59-A:792-801.

9. Locker B, Galaud B. Complications de l'arthroscopie de hanche. In: Arthroscopie. Paris: Elsevier, 2006:315-17.

10. Anract $\mathbf{P}$, Katabi M, Forest $\mathbf{M}$, et al. Synovial chondromatosis and chondrosarcoma: a study of the relationship between these two diseases. Rev Chir Orthop Reparatrice Appar Mot 1996;82:216-24 (in French).

11. Taconis WK, van der Heul RO, Taminiau AM. Synovial chondrosarcoma: report of a case and review of the literature. Skeletal Radio/ 1997;26:682-5.

12. Wuisman PI, Noorda RJ, Jutte PC. Chondrosarcoma secondary to synovial chondromatosis: report of two cases and a review of the literature. Arch Orthop Trauma Surg 1997;116:307-11.

13. Gilbert SR, Lachiewicz PF. Primary synovial osteochondromatosis of the hip: report of two cases with long-term follow-up after synovectomy and a review of the literature. Am J Orthop 1997:26:555-60.

14. Knoeller SM. Synovial osteochondromatosis of the hip joint: etiology, diagnostic investigation and therapy. Acta Orthop Belg 2001;67:201-10.

15. MacCarthy E, Dorfmann H. Primary synovial chondromatosis: an ultrastructural study. Clin Orthop 1982;168:178-86.

16. Mohr W. Is synovial osteo-chondromatosis a proliferative disease? Pathol Res Pract 2002;198:585-8.

17. Villacin AB, Brigham LN, Bullough PG. Primary and secondary synovial chondrometaplasia: histopathologic and clinicoradiologic differences. Hum Pathol 1979;10:439-51.

18. Doward DA, Troxell ML, Fredricson M. Synovial chondromatosis in an elite cyclist: a case report. Arch Phys Med Rehabil 2006;87:860-5.

19. Gille J, Krueger S, Aberle J, et al. Synovial chondromatosis of the hip: a case report and clinicopathologic study. Acta Orthop Belg 2004;70:182-8. 
20. Krebs VE. The role of hip arthroscopy in the treatment of synovial disorders and loose bodies. Clin Orthop 2003;406:48-59.

21. Witwity T, UhImann RD, Fischer J. Arthroscopic management of chondromatosis of the hip joint. Arthroscopy 1988;4:55-6.

22. Dienst M, Kohn D. Hip arthroscopy: minimal invasive diagnosis and therapy of the diseased or injured hip joint. Unfallchirurg 2001;104:2-18 (in German).

23. Gouin F, Baudry C, Collet T, Delecrin J, Passutin N. L'arthroscopie de hanche: a propos de 30 cas. Ann Orthop Ouest 2003;35:139-44.
24. Schoeniger R, Naudie DD, Siebenrock KA, Trousdale RT, Ganz R. Modified complete synovectomy prevents recurrence in synovial chondromatosis of the hip. Clin Orthop 2006;451:195-200

25. Lim SJ, Chung HW, Choi YL, et al. Operative treatment of primary synovial osteochondromatosis of the hip. J Bone Joint Surg [Am]2006;88-A:2456-64.

26. Dorfmann H, De Bie B, Bonvarlet JP, Boyer T. Arthroscopic treatment of synovial chondromatosis of the knee. Arthroscopy 1989:5:48-51. 